\title{
Food Safety Training Needs at Evacuation Shelters Operated by Faith-Based Organizations
}

\author{
Junehee Kwon, $\mathrm{PhD}, \mathrm{RD}$ \\ Department of Hospitality \\ Management and Dietetics \\ Kansas State University \\ Lisa Zottarelli, PhD \\ Department of Sociology and Social Work \\ Texas Woman's University \\ Sockju Kwon, PhD, RD \\ Department of Biomedical Sciences \\ Missouri State University \\ Yee Ming Lee, PhD \\ Department of Nutrition, Dietetics, \\ and Hospitality Management \\ Auburn University \\ Dojin Ryu, PhD \\ School of Food Science \\ University of ldaho
}

\section{A b st r a ct The authors conducted a survey to identify food safety} training needs at evacuation shelters operated by faith-based organizations (FBOs) in four hurricane-prone states. Five thousand randomly selected FBO leaders were asked questions about their food safety attitudes and food handling practices at evacuation shelters. Descriptive statistics and multivariate analysis of variance were calculated to summarize and prioritize the responses. Results from 138 leaders revealed that on average, $590 \pm 4,787$ evacuees were served for $36 \pm 72$ days at FBO-operated shelters. Only $19.6 \%$ felt they were well prepared for the shelter. Only $5.8 \%$ had professional food preparation staff and many accepted hot $(47.8 \%)$ and cold $(37 \%)$ prepared food donations. Some lacked adequate refrigerator (18.8\%) or freezer (16.7\%) spaces, but $40 \%$ kept hot food leftovers for later use. The majority did not provide food safety training before opening the shelters $(73.2 \%)$, yet $76.9 \%$ said they will provide food to evacuation shelters again. The results show a need for food safety training and specific strategies for training at FBOs.

\section{Introduction}

Recent foodborne illness statistics show improvement in food safety in the U.S. (Scallan et al., 2011). In 1999, the Centers for Disease Control and Prevention (CDC) estimated 76 million cases of foodborne illnesses had been occurring each year in the U.S., along with 325,000 hospitalizations and 5,000 deaths (Mead et al., 1999). Through systematic efforts across the food safety continuum from agricultural industries to regulatory agencies, safety of food in the U.S. has improved signifi- cantly. CDC now estimates that each year in the U.S. 9.4 million foodborne illness cases, 55,961 hospitalizations, and 1,351 deaths are caused by the 31 most prevalent foodborne pathogens (Scallan et al., 2011).

As the general safety of food supplies in the U.S. improves, today's food safety researchers have focused on improving the food safety of high-risk populations or institutions where the most vulnerability exists. All food service establishments must provide food safety training to their employees and receive food safety inspections provided by local or state government officials. For nonprofit organizations such as faith-based organizations, however, where food is served by volunteers on an as-needed basis, it is difficult to enforce food safety training and therefore such organizations face additional challenges related to their ability to ensure food safety.

Over the past several decades, numerous Americans have been afflicted by natural disasters such as hurricanes, tropical storms, wild fires, and floods. The National Weather Service (NWS) of the National Oceanic Atmospheric Administration (NOAA) reported that the average number of tropical storms and major hurricanes has increased since 1851 (Blake, Rappaport, \& Landsea, 2007; Webster, Holland, Curry, \& Chang, 2005). In 2005, 28 reported cases of tropical storms and 15 hurricanes occurred, which included two of the most devastating hurricanes, Katrina and Rita (Blake et al., 2007). The death tolls caused by weather-related natural disasters were also significant, as 566 people died in 2008 and 366 people died in 2009 (Redmond \& Griffith, 2003). Natural disasters caused a large monetary loss from crop and property damages. In 2008 and 2009, severe weather resulted in $\$ 26.5$ billion and $\$ 7.5$ billion worth of damages, respectively (National Weather Service [NWS], 2010a, 2010b).

The evacuees who were displaced from their homes following natural disasters experienced physical and emotional stress due to the sudden decrease in available resources and 
compromised living conditions (Sanders, 2007) such as limited access to showers, toilets, communal dining rooms, and long lines for services. Among the major concerns in the aftermath of the disasters were public health issues, such as the outbreak of communicable diseases (U.S. Department of Homeland Security [DHS], 2008a). Communicable diseases such as norovirus and Salmonella were reported by Hurricane Katrina evacuees (Centers for Disease Control and Prevention [CDC], 2005a, 2005b). For 11 days after Hurricane Katrina, over $1,000(18 \%)$ of the 6,500 visits to doctors at the Reliant Park Medical Clinic in Houston had to do with treating cases of diarrhea or vomiting (Gavagan et al., 2006); two confirmed cases of toxigenic Vibrio cholerae infections also occurred (CDC, 2006).

Compared with other groups, vulnerable populations-including individuals with HIV or immune-compromising conditions, pregnant women, infants, and individuals with diabetes and other disabilities—are more easily affected by foodborne illnesses in the event of evacuation. Researchers showed a significant association between pregnant women from hurricane-affected areas in Louisiana, Mississippi, and Alabama and the number of pregnant women giving birth to underweight babies (Callaghan et al., 2007). Statistics also showed that the majority of the Hurricane Katrina evacuees who resided in Houston shelters were lowincome, less-educated, and uninsured single minorities with children (Brodie, Weltzien, Altman, Blendon, \& Benson, 2006). Based on these findings, researchers concluded that the need existed for more thorough health care planning and food handling training. To prevent the spreading of infectious diseases in the shelters, proper hand washing and the use of hand sanitizers before meals were recommended (Sanders, 2007). The main transmission routes for many communicable diseases were fecal-oral contaminations through contaminated water or food (Stephen \& Brown, 2005).

County, state, and federal government agencies including the Federal Emergency Management Agency (FEMA) disbursed large amounts of financial aid in the relief efforts for evacuees. Even so, these agencies still needed help from nonprofit organizations and social services in order to provide food and shelter to the disaster victims (DHS, 2008a, 2008b). For instance, the Salvation Army's data showed that the organization served 5.6 million meals to people affected by Hurricane Katrina (Salvation Army, 2009).

Alongside the public relief effort, many private organizations, including faith-based organizations (FBOs), provided assistance voluntarily. In 2008, Pant and co-authors examined the FBO-operated shelters in Mississippi and reported that FBOs were capable of determining the needs of evacuees, had more flexibility in decision making, and had an easier time recruiting volunteers than other relief organizations. These researchers also reported inadequate disaster education and training in those shelters, however (Pant, Kirsch, Subbarao, Hsieh, \& Vu, 2008).

The lack of volunteer training in relief efforts may present food safety challenges. A metaanalysis and a review of previous research studies showed that cross contamination, personal hygiene, and consumption of raw or uncooked food items were common among the general public (Patil, Cates, \& Morales, 2005; Redmond \& Griffith, 2003). Finch and Daniel (2005) contended that the risk of foodborne illnesses in the emergency operations increased because of donated food that passed through multiple points in transition, emergency food workers' lack of food safety knowledge, and improper food handling behaviors.

Major hurricanes affected large areas across several states, necessitating evacuation shelters operated by FBOs in affected areas; however, little is known about food handling practices and food safety training at those evacuation shelters. Therefore, our study was designed to assess food handling practices and to identify training needs for FBO leaders and volunteers who provide evacuation shelters in four major hurricane-prone states: Texas, Alabama, Mississippi, and Louisiana. The specific objectives were (a) to assess food handling practices at evacuation shelters, (b) to identify food types and/or services provided to evacuees, (c) to investigate the attitudes of FBO leaders regarding food safety risk during disasters and future plans, and (d) to identify food safety training needs at evacuation shelters operated by FBOs.

\section{Methods}

\section{Survey Instrument Development and Pilot Study}

A survey questionnaire was developed based on a previous telephone survey instrument
(Kwon, Ryu, \& Zottarelli, 2007). The content of the survey questionnaire was validated by the researchers, including experts in food safety and emergency preparedness. The questionnaire included questions on (a) the demographic characteristics of participants and FBO facilities; (b) past evacuation shelter operation data, including information on the major disasters that the shelters provided services for, the number of evacuees at the peak of the operation, the duration of the evacuation shelter operation, and the personnel for food production and distribution; (c) food handling practices at the evacuation shelters, such as food acquisition, storage, preparation, and distribution, the most often served menu items, and food safety training at the shelter operations; (d) attitudes toward food safety risks and the shelter's future evacuation operation plans; and (e) preferred food safety training media and methods.

Although the researchers planned telephone surveys, the initial pilot study revealed that a telephone interview format was not an effective way to reach potential respondents. To improve responses from FBO leaders and organizer, the researchers then converted the telephone survey to a printed survey format, which was mailed. A pilot study with a mailed survey format was conducted with 20 area FBOs to ensure its usability and to evaluate the inter-item reliability of the instrument prior to data collection. The instrument was revised to reflect minor format and text changes based on the pilot study.

\section{Sample Selection and Data Collection} Because no available list existed of FBOs that provided food and overnight shelter for evacuees from various disasters, researchers collected the contact information of FBOs in four hurricane-prone states (i.e., Texas, Alabama, Mississippi, and Louisiana) through Web sites and the yellow pages. Contact information for over 50,000 organizations was collected from which 5,000 FBOs were randomly selected as the study sample. A copy of the printed questionnaire, a postagepaid envelope, and a cover letter were sent to leaders of 5,000 FBOs. A postcard was also included for a quick response in case any of the contacted FBOs did not provide an evacuation shelter. Follow-up postcards were sent three weeks later to encourage participation. Participation was also encouraged with 
an incentive of a $\$ 20$ gift card to a national retailer of the respondent's choice upon completion of the survey.

\section{Statistical Analysis}

SPSS for Windows (version 17.0, 2008) was used for statistical analyses. Descriptive statistics such as frequencies, means, standard deviations, and cross tabulation were conducted to summarize the data. A repeated measure of multiple analysis of variance (MANOVA), together with Bonferroni posthoc analysis, was conducted to compare different variables within a group. The statistical significance was determined at $p<.05$.

\section{Results}

\section{Response Rate and Demographic Characteristics of FBOs}

Of the 5,000 mailed surveys, 704 were undeliverable due to incorrect contact information. A total of 423 participants responded (9.8\% response rate) and, of those, 285 FBOs did not offer evacuation shelters (6.6\%). Only 138 responses were usable for data analysis (3.2\% completion rate).

The majority of the participants identified themselves as Christians ( $n=112,81.2 \%$ ). About one-half of these Christian respondents were Baptists $(n=61,47.3 \%)$. Most Christian organizations were Protestant, while a small number were Catholic $(n=5,3.6 \%)$. A few participants identified themselves as Muslim $(n=3,2.2 \%)$ or affiliated with other religions $(n=9,6.5 \%)$. The number of FBO members ranged from 5 to 4,000 , with an average congregation size of 400 . The majority of the respondents $(n=119,86.2 \%)$ claimed that the income level of the congregation was low.

\section{Experience of FBOs During Disasters}

On average, the FBOs served 590 evacuees (mean \pm standard deviation $[S D]=590 \pm$ 4,787 ; median $=27$ ) with food and overnight shelter for 36 days $(S D=72$ days; median $=$ 14 days). Evacuation shelters were provided for various disasters, including Hurricane Katrina $(n=119,86.2 \%)$ and Hurricane Rita $(n=64,46.4 \%)$. Other disasters included hurricanes, local chemical disasters, and other unspecified disasters ( $n=40,29.0 \%$ ). Nearly one-half of FBOs experienced interruption of electricity $(n=57,41.3 \%)$, water $(n=26,18.8 \%)$, and other utilities $(n=10$,

\begin{tabular}{|c|c|c|}
\hline \multicolumn{3}{|c|}{$\begin{array}{l}\text { Experience of Faith-Based Organizations (FBOs) During Disasters } \\
(N=138)\end{array}$} \\
\hline Experience & \# Facilities ${ }^{\mathrm{a}}$ & $\%$ \\
\hline \multicolumn{3}{|l|}{ Number of evacuees served at peak ${ }^{\mathrm{a}}$} \\
\hline 50 or less & 69 & 50.0 \\
\hline $51-100$ & 17 & 12.3 \\
\hline $101-200$ & 8 & 5.8 \\
\hline More than 200 & 15 & 10.9 \\
\hline \multicolumn{3}{|l|}{ Number of days that the evacuation shelter was operated ${ }^{a}$} \\
\hline 30 or less & 77 & 55.8 \\
\hline $31-60$ & 16 & 11.6 \\
\hline More than 60 & 11 & 8.0 \\
\hline \multicolumn{3}{|l|}{ Number of FB0s provided food and shelter for evacuees during: ${ }^{\text {b }}$} \\
\hline Hurricane Katrina & 119 & 86.2 \\
\hline Hurricane Rita & 64 & 46.4 \\
\hline Other disasters & 40 & 29.0 \\
\hline \multicolumn{3}{|l|}{ Interruption of services during disasters } \\
\hline Electricity & 57 & 41.3 \\
\hline Water & 26 & 18.8 \\
\hline Utility & 10 & 7.2 \\
\hline Number of FBOs provided training on emergency shelter management & 72 & 52.2 \\
\hline Number of FBOs provided training on food safety & 37 & 26.8 \\
\hline \multicolumn{3}{|l|}{ Preparedness to provide food and shelters to evacuees ${ }^{a}$} \\
\hline Very prepared & 27 & 19.6 \\
\hline Somewhat prepared & 84 & 60.9 \\
\hline Not prepared at all & 21 & 15.2 \\
\hline \multicolumn{3}{|c|}{$\begin{array}{l}\text { aThe number of total responses to each question may be less than } 138 \text { due to missing data or "I don't know" response } \\
\text { 'The number of total responses to this question exceeds } 138 \text { due to multiple answers. }\end{array}$} \\
\hline
\end{tabular}

$7.2 \%$ ) during the disasters. About one-half of the FBO leaders did not receive emergency shelter management training ( $n=66,47.8 \%)$. To the question asking how prepared respondents were before providing food and shelter, $19.6 \%$ of the respondents replied that they were "very prepared," $60.9 \%$ said that they were "somewhat prepared," and 15.2\% said that they were "not prepared at all (Table 1)."

\section{Food Handling Practices in Evacuation Shelters}

Food was prepared mostly by volunteer members of the FBOs $(n=87,63.0 \%)$, community volunteers $(n=39,28.3 \%)$, and evacuees ( $n$ $=37,26.8 \%$ ) at the shelter. More than $70 \%$ of the FBO shelters $(n=101,73.2 \%)$ received commercially canned or dry food donated to the shelters. Many FBOs also received donations of prepared food items from FBO mem- bers and community volunteers. The donated items included hot food items such as casseroles and cooked vegetables ( $n=66,47.8 \%$ ); prepared salads or other cold food $(n=51$, $37.0 \%$ ); uncooked meat, chicken, eggs, and fish items ( $n=51,37.0 \%)$; and home canned or dried food $(n=36,26.1 \%)$. Only a small number of FBOs used professional cooks ( $n$ $=8,5.8 \%)$ and received prepared food from restaurants and retailers ( $n=19,13.8 \%)$.

More than half of the respondents $(n=78$, $56.5 \%$ ) did not receive any food safety training before operating the evacuation shelter for the last disaster. Of these respondents, $21 \mathrm{FBOs}(15.2 \%)$ offered food safety training after the last disaster. They stated that food safety training was given by the Red Cross, health departments, or the headquarters of their affiliated religious organizations. Even though 66 FBOs accepted prepared hot and 


\section{TABLE 2}

\section{Food Handling Practices at Faith-Based Organizations (FBOs) During Disasters $(N=138)$}

\section{Food Handling Practices}

\# Facilities

\section{$\%$}

Persons who cooked for shelters (mark all that apply)a

\begin{tabular}{|c|c|c|}
\hline Members of your organization cooked at the shelter & 87 & 63.0 \\
\hline Community volunteers cooked at the shelter & 39 & 28.3 \\
\hline Evacuees cooked at the shelter & 37 & 26.8 \\
\hline Restaurants and retailers donated prepared foods & 19 & 13.8 \\
\hline Professional cooks cooked at the shelter & 8 & 5.8 \\
\hline Designated person in charge of food preparation & 78 & 56.5 \\
\hline \multicolumn{3}{|l|}{ Types of donated food items (mark all that apply) ${ }^{\mathrm{a}}$} \\
\hline Commercially canned or dry food & 101 & 73.2 \\
\hline Prepared hot food such as casseroles or cooked vegetables & 66 & 47.8 \\
\hline Fresh fruits and vegetables & 57 & 41.3 \\
\hline Frozen food & 54 & 39.1 \\
\hline Meat, chicken, eggs, and fish items & 51 & 37.0 \\
\hline Prepared salads or cold sandwiches & 51 & 37.0 \\
\hline Home canned or dried food & 36 & 26.1 \\
\hline Food handling guidelines provided to donors & 13 & 9.4 \\
\hline Inadequate refrigerated space for food & 26 & 18.8 \\
\hline Inadequate freezer space for food & 23 & 16.7 \\
\hline \multicolumn{3}{|l|}{ Type of service methods used at most meal times ${ }^{b}$} \\
\hline Cafeteria (using service personnel) & 51 & 37.0 \\
\hline Buffet (self-service) & 38 & 27.5 \\
\hline Family style (using bowls or platters at the table) & 19 & 13.8 \\
\hline Others & 12 & 8.7 \\
\hline \multicolumn{3}{|l|}{ Typical serving time for evening meals ${ }^{\mathrm{b}}$} \\
\hline 30 minutes or shorter & 9 & 6.5 \\
\hline $31-60$ minutes & 31 & 22.5 \\
\hline $61-90$ minutes & 22 & 15.9 \\
\hline $91-120$ minutes & 22 & 15.9 \\
\hline $120-180$ minutes & 19 & 13.8 \\
\hline 181 minutes or longer & 4 & 2.9 \\
\hline FB0s kept leftover food for later use & 55 & 39.9 \\
\hline
\end{tabular}

cold food items from their members and congregations, only 13 FBOs (9.4\%) provided food handling guidelines to their food donors. About one-half of the respondents had designated persons in charge of food preparation at the shelters $(n=78,56.5 \%)$.

A significant number of respondents indicated that they did not have adequate refrigerator $(n=26,18.8 \%)$ or freezer space $(n=23$, $16.7 \%$ ) to store food items. Of these respondents, 15 facility leaders (10.9\%) noted they lacked both refrigerator and freezer spaces for donated and prepared food items during their operation. When cold storage space was inadequate, FBO leaders stated that they (a) provided only canned/dry goods to evacuees, (b) used coolers filled with ice cubes for storage, (c) received a limited amount of food to be used for a meal or a day, (d) consumed food as quickly as possible, (e) rented refrigerated trucks, (f) used refrigerators at members' homes, and (g) sent food items to other shelters. Table 2 summarizes the food handling practices including food acquisition and storage practices at evacuation shelters operated by FBOs.

\section{Types of Food or Services Provided to Evacuees}

The frequency of types of food being served was asked and analyzed using a repeated measures MANOVA item analysis. The results showed a significant difference in the frequency of certain types of food being served $(F=17.9, p<.001)$. The pairwise comparison among types of food showed that casseroles, mashed potatoes, macaroni and cheese, or rice and beans were served often or very often at shelters $(n=72,52.2 \%)$ and these items were significantly more often served than soups (e.g., gumbo and chowder) $(\Delta=0.423$, $p=.003$ ), roasted or baked entrées (e.g., beef, meat loaf, and turkey) $(\Delta=0.606, p<.001)$, and cold protein/starch salad (e.g., chicken salad and potato salad $)(\Delta=0.925, p<.001)$. Hamburgers or chicken sandwiches were also served often to very often by many FBOs ( $n$ $=55,39.9 \%)$ and these items were served more often than cold protein/starch salad $(\Delta$ $=0.625, p<.001)$. Soup items were served more often than cold protein/starch salad $(\Delta$ $=0.500, p=.002)$ (Table 3).

These food items were mostly served cafeteria style and defined as a designated person(s) serving food to evacuees at most meal times ( $n=51,37.0 \%)$ or buffet style as self-service $(n=38,27.5 \%)$. Other serving styles included mixed serving styles, delivery from restaurants, and distribution of canned/ dry goods. The majority of the shelters served meals within one hour $(n=40,29.0 \%)$ or within two hours $(n=84,60.9 \%)$. Twentythree shelters were serving meals longer than within two hours $(n=23,16.7 \%)$. The majority of the participants reported, however, that they were also able to keep food hot during meal times $(n=103,74.6 \%)$. Many FBOs kept leftover food for later use ( $n=55,39.9 \%)$. Among the 55 FBOs that kept leftover food, 16 were shelters without adequate refrigerator or freezer space (Table 2).

\section{Attitudes of FBO Leaders Regarding Food Safety Risk and Future Plans}

Only five of the FBO leaders (3.6\%) who provided evacuation shelters recognized an increased risk of foodborne illnesses at the evacuation shelters. The rest of the participants thought that their shelters would not experience foodborne illness outbreaks because they prepared food carefully, served food immediately, and discarded leftovers just 
as they did at home. Some also rationalized that no foodborne illness would occur because their food was prepared by ServSafe-certified evacuees or experienced food handlers. Others mentioned that food safety would be ensured as long as they kept practicing good hygiene, washing hands, or using sanitizers. More than three-fourths of the FBO leaders were likely or very likely to serve evacuees again in the future $(n=106,76.8 \%)$. Most of them would like to receive free food safety education materials ( $n$ $=104,75.4 \%$ ). Only 21 out of 54 FBO leaders who did not have a designated person in charge of food preparation in the past were willing to designate a person who would be responsible for food preparation in the future (Table 4).

The majority of the respondents who showed interest in receiving food safety education materials identified DVD as their preferred format. The repeated measures MANOVA shows that DVD was preferred over all other formats $(F=$ $21.1, p<.001$ ), whereas web-based training was least preferred (Table 5). Eighteen FBO leaders (13.0\%) indicated that they need education materials in a language other than English. Of these respondents, 10 needed a Spanish version of food safety education materials.

\section{Discussion and Conclusion}

No specific data indicated to what extent FBOs were involved in evacuation shelter operations during disasters. Therefore, researchers randomly selected contact information for 5,000 FBO leaders, including various religious groups in four hurricaneprone states. Researchers were only able to collect 138 completed questionnaires from FBO leaders, however. The small number of completed questionnaires may indicate that only a limited number of FBOs participated in evacuation shelter operations or that FBOs were not involved in recent evacuation shelter operations and, therefore, little interest existed in this topic. Unlike the pilot study that was conducted immediately after a major hurricane (Kwon et al., 2007), a lack of interest was prominent during our initial pilot study where researchers were not successful in securing individuals who were interested in participating. Not having an inclusive list of FBOs that participated in evacuation shelter operations made it extremely difficult to secure a larger sample and, because of this limitation, the results from this study must be interpreted with caution.

\section{TABLE 3}

\section{Types of Food Served at Faith-Based Organizations During Disasters $(N=138)$}

Types of Food

\begin{tabular}{|l|c|}
\hline & $\boldsymbol{F}=\mathbf{1 7 . 9 ;} \boldsymbol{p}<. \mathbf{0 0 1 ^ { * }}$ \\
\hline Casseroles, mashed potatoes, macaroni and cheese, or rice and beans & $3.56 \pm 1.21^{\mathrm{a}}$ \\
\hline Hamburger or chicken sandwiches & $3.24 \pm 1.21^{\text {ab }}$ \\
\hline Soups and stews such as gumbo and chowder & $3.12 \pm 1.26^{\mathrm{b}}$ \\
\hline Roast beef, meat loaf, or roast turkey & $2.93 \pm 1.19^{\mathrm{bc}}$ \\
\hline Chicken salad, tuna salad, or potato salad & $2.62 \pm 1.19^{\mathrm{c}}$ \\
\hline
\end{tabular}

Note. A Likert style scale was used: 1 , never; 2 , rarely; 3 , sometimes; 4 , often; and 5 , very often. $S D=$ Standard deviation.

*Statistical significance was determined by a repeated measure MANOVA item analysis with Bonferroni post hoc analysis. Values with different superscripts are significantly different between paired variables.

\section{TABLE 4}

\section{Attitudes of Faith-Based Organization Leaders Toward Food Safety Risks and Future Plans for Shelter Operation $(N=138)$}

\begin{tabular}{|c|c|c|}
\hline Food Handling Practices & \# Facilities & $\%$ \\
\hline $\begin{array}{l}\text { Leaders recognizing an increased risk of foodborne illness while } \\
\text { at shelter }\end{array}$ & 5 & 3.6 \\
\hline \multicolumn{3}{|l|}{ Willingness to serve evacuees again in the future $\mathrm{a}^{\mathrm{a}}$} \\
\hline Very likely & 67 & 48.6 \\
\hline Likely & 39 & 28.3 \\
\hline Undecided & 10 & 7.2 \\
\hline Unlikely & 10 & 7.2 \\
\hline
\end{tabular}

Willingness to designate a person in charge of food preparation

in the future ${ }^{\mathrm{a}, \mathrm{b}}$

\begin{tabular}{|l|c|c|}
\hline Yes & 21 & 37.5 \\
\hline No & 25 & 44.6 \\
\hline Undecided & 10 & 17.9 \\
\hline Willingness to receive free food safety education materials & 104 & 75.4 \\
\hline
\end{tabular}

aThe number of total responses to each question may be less than 138 due to missing data or "I don't know" response. ${ }^{\mathrm{b} P e r c e n t a g e}$ of answers to this question were calculated based on the total number of respondents who did not have a designated person responsible for food preparation at the last evacuation shelter operation $(n=56)$.

\section{Identified Food Safety Risks}

Through our data, food safety risks at evacuation shelters operated by FBOs in hurricaneprone states were identified. It was apparent that food safety training was not adequately provided to volunteers who are members of the general public. Previous studies showed inadequate food handling practices for the general public (Kwon, Wilson, Bednar, \& Kennon, 2008; Patil et al., 2005; Redmond
\& Griffith, 2003). Therefore, the lack of food safety training may present an increased risk for foodborne illness for a large group of people served at these volunteer-run operations. Our data show that limited training for volunteers was provided prior to evacuation shelter operations ( $n=37,26.8 \%)$.

Our data also show potential food safety risks through the flow of food from acquisition to service and postservice handling of 


\section{TABLE 5}

\section{Preferred Formats of Food Safety Training for Faith-Based Organizations $(N=138)$}

\section{Formats of Training}

\begin{tabular}{|l|c|}
\hline & $\boldsymbol{F}=\mathbf{2 1 . 1} ; \boldsymbol{p}<. \mathbf{0 0 1}^{\text {* }}$ \\
\hline DVD & $4.42 \pm 0.93^{\mathrm{a}}$ \\
\hline Computer-based CD & $3.83 \pm 1.05^{\mathrm{b}}$ \\
\hline Videotapes & $3.75 \pm 1.17^{\mathrm{bc}}$ \\
\hline Lectures & $3.59 \pm 1.00^{\mathrm{bc}}$ \\
\hline Web-based training & $3.49 \pm 1.12^{\mathrm{c}}$ \\
\hline
\end{tabular}

Note. A Likert style scale was used: 1 , definitely not; 2 , probably; 3 , unsure; 4, likely; and 5 , very likely. $S D=$ standard deviation.

*Statistical significance was determined by a repeated measure MANOVA item analysis with Bonferroni post-hoc analysis. Values with different superscripts are significantly different between paired variables.

food. Food acquisition at evacuation shelters operated by FBOs raises additional challenges due to donated food items that are prepared by individuals who may not have good food handling practices. In those cases, the extended time between preparation and service increases the food safety risk. Food safety experts contend that food items transferred from one place to another are more likely to be exposed and held at an unsafe temperature (Medeiros, Kendall, Virginia, Chen, \& Dimascola, 2001). By allowing prepared food items to be donated at FBO-operated shelters, it is conceivable that additional food safety risks may exist. Therefore, the need to train FBO staff on safe food handling practices will also increase. Less than $10 \%$ of FBO leaders indicated that they provided some sort of guidelines for food donors (9.4\%).

About one-fourth of FBOs reported that they did not have adequate refrigerator and/ or freezer space for food storage in the shelters $(n=34,24.6 \%)$. The situation could be worse with the power outages that were reported by many of our participants. Power outages happened frequently in areas affected by hurricanes and other disasters. In our study, about $40 \%$ of the FBOs experienced electricity interruption (Table 1). Other reports showed that the power supply in the hospitals in New Orleans could only be regained four days after the disaster (Rodríguez, Trainor, \& Quarantelli, 2006). Generators were used when power outages occurred, but this usage was often limited. Hurricane Isabel left 80,000 Virginia residents living in the affected areas without electricity for more than one week (Franke \& Simpson, 2004). FBO leaders need to be informed about safe food storage methods so that they will be sure to accept only food items that can be stored safely and maintain safe storage temperatures for time and temperature control for safety (TCS) food items.

Although we did not ask about personal hygiene practices at the shelter operations, food prepared and served by volunteers and evacuees may increase the potential of contamination from food handlers. Personal hygiene is one of the major challenging areas in consumer food handling practices (Patil et al., 2005; Redmond \& Griffith, 2003) and potential contamination by consumers may be further increased by utilizing self-service and family-style service options, which were frequently used by our participants $(n=57$, 41.3\%). A case study conducted by Dippold and co-authors (2003) showed that a lack of sneeze guards at the buffet line, which act as a barrier between individuals and the food served, could have contributed to an outbreak of gastroenteritis. Since most of the food at the evacuation shelters was served using cafeteria style $(n=51 ; 37 \%)$ and buffet style ( $n$ $=38,27.5 \%$ ), installing a sneeze guard at the serving line might also be a plausible way to prevent an outbreak of foodborne illness.

The types of frequently served food also indicate a need for food safety training. The most frequently served food items were mixed dishes, such as casseroles, mashed potatoes, and macaroni and cheese. Time and temperature control for these types of food is important. To ensure adequate cooking $\left(165^{\circ} \mathrm{F}\right)$, FDA's Food Code suggests a higher internal temperature for these items than for other dishes. Cooling and reheating these dense food items are also challenging. The majority of the evacuation shelters served these food items often or very often $(n=72$, $52.2 \%$ ). Of these shelters, 33 FBOs kept their leftover food for later service. Moreover, 16 out of 34 shelters with no refrigerator or freezer space reported that they kept the leftover food for later use (Table 2). Considering the difficulties in cooling and reheating these items, and with improper cooling being one of the main reasons for foodborne illness outbreaks, to ensure food safety it is imperative for evacuation shelter operators to follow safe cooling and reheating processes.

Reserving leftover food was common in the shelters. It was unknown how the FBOs detected the spoilage of the leftovers. Even so, other studies showed that consumers usually used sensory elements, such as smell and taste, to judge if the leftover food items were safe to consume (Bruhn \& Schutz, 1999). If the leftover food items were not cooled and reheated adequately or if spoilage went undetected, foodborne illness would likely occur.

Other factors such as physical disability can also impact whether or not evacuees receive the assistance they need. Previous literature showed that individuals with disabilities might not be able to react promptly and might have a delayed response time when natural disasters occurred (Chou et al., 2004), thereby preventing them from reaching the shelter or from being able to take advantage of the food and clean water offered by the FBOs.

Meanwhile, the extreme living environment created by the natural disasters (e.g., lack of access to clean water and inadequacy of food) also increased the risk of morbidity and mortality among other venerable populations, such as those with chronic diseases, older adults, pregnant women, and infants (Aldrcih \& Benson, 2008; Mokdad et al., 2003, 2005). Even though the composition of the evacuees residing in the evacuation shelters run by our respondents was unknown, previous statistics indicated that $41 \%$ evacuees of Hurricane Katrina had some chronic diseases and most of them were elderly (The Henry J. Kaiser Foundation, 2005). Increased 
risks for foodborne illnesses due to living environment and high-risk constituents in these shelters make it imperative that food safety training be provided to volunteers as a preventive measure.

\section{Risk Perception and Future Plan}

Many respondents underestimated the risk of foodborne illness at the shelters. Studies have shown that consumers are confident about the safety of home-prepared food. They perceive that foodborne illness is more likely to occur from food eaten away from home (Fein, Lin, \& Levy, 1995). FBO leaders also thought that less risk of foodborne illness existed if they handled food items the way they were handled at home. It has been found, however, that consumers do not always cook, heat, or cool food properly; they serve contaminated food items; they purchase food from unsafe sources; and they adopt poor hygiene practices (Bryan, 1988). Some respondents in our study believed that food prepared by ServSafecertified employees was safe. Although evidence has shown that employees who obtain food safety certification have better food safety knowledge, challenges persist, and further motivation is needed to ensure safe food handling (Raval-Nelson \& Smith, 1999).

Despite the fact that participants did not recognize foodborne illness risks, it was apparent that many of our participants planned to provide evacuation shelters again in the future. FBOs play an integral role during large disasters, and reaching out to these organizations with user-friendly, useful food safety training materials may enhance food handling practices, thus reducing potential foodborne illnesses. Our participants have identified the DVD format as the most preferred method for food safety training. Although the Internet has become more popular lately, web-based training was preferred the least by FBO leaders.

\section{Implication and Limitations}

Our data indicated that training is needed for FBOs to ensure food safety throughout the entire stage of food preparation and serving. From the acquisition of food that includes prepared hot and cold food items that are donated to evacuation shelters to the cooling and reserving of leftover food, food safety training for these organizations is necessary. Findings from our study provided some information for prioritizing food safety training contents for leaders and volunteers in evacuation shelters operated by FBOs based on operational data. Food safety training for FBOs may focus on handling donated food items, safe storage, and handling TCS food items.

Despite our efforts to reflect food handling practices in a representative sample of $\mathrm{FBOs}$, the low participation rate for our study makes it difficult to generalize our findings; therefore, the data must be interpreted with caution. Nonetheless, our study surveyed and introduced food handling practices and conditions at evacuation shelters operated by volunteers and $\mathrm{FBO}$ members in hurricane-prone states. For future research, we suggest investigating food handling practices and food safety training needs for individuals working in evacuation shelters operated by public organizations other than FBOs as our study does not address these groups' training needs. Future research should also focus on refining food safety training priorities, developing and implementing food safety training programs, and evaluating the effectiveness of such training programs.

Acknowledgement: This project was funded by U.S. Department of Agriculture National Integrated Food Safety Initiative Grant (\#2007-51110-03818).

Corresponding Author: Junehee Kwon, Associate Professor, Department of Hospitality Management and Dietetics, Kansas State University, 108 Justin Hall, Manhattan, KS 66506-1404. E-mail: jkwon@ksu.edu.

\section{References}

Aldrich, N., \& Benson, W.F. (2008). Disaster preparedness and the chronic disease needs of vulnerable older adults. Preventing Chronic Disease, 5(1), 1-7.

Blake, E.S., Rappaport, E.N., \& Landsea, C.W. (2007). The deadliest, costliest, and most intense United States tropical cyclones from 1851 to 2006 (and other frequently requested hurricane facts). Retrieved from http://www.nhc.noaa.gov/pdf/NWS-TPC-5.pdf

Brodie, M., Weltzien, E., Altman, D., Blendon, R.J., \& Benson, J.M. (2006). Experiences of Hurricane Katrina evacuees in Houston shelters: Implications for future planning. American Journal of Public Health, 96, 1402-1408.

Bruhn, C.M., \& Schutz, H.G. (1999). Consumer food safety knowledge and practices. Journal of Food Safety, 19, 73-87.

Bryan, F. (1988). Risks associated with vehicles of foodborne pathogens and processes that lead to outbreaks of foodborne diseases. Journal of Food Protection, 51, 663-673.

Callaghan, W.M., Rasmussen, S.A., Jamieson, D.J., Ventura, S.J., Farr, S.L., Sutton, P.D., Mathews, T.J., Hamilton, B.E., Shealy, K.R.,
Brantley, D., \& Posner, S.F. (2007). Health concerns of women and infants in times of disasters: Lessons learned from Hurricane Katrina. Maternal and Child Health Journal, 11(4), 307-311.

Centers for Disease Control and Prevention. (2005a). Infectious disease and dermatologic conditions in evacuees and rescue workers after Hurricane Katrina-multiple states, August-September, 2005. Morbidity and Mortality Weekly Report Dispatch, 54, 1-4.

Centers for Disease Control and Prevention. (2005b). Norovirus outbreak among evacuees from hurricane Katrina-Houston, Texas, September 2005. Morbidity and Mortality Weekly Report, 54(40), 1016-1018.

Centers for Disease Control and Prevention. (2006). Two cases of toxigenic Vibrio cholerae Ol infection after Hurricanes Katrina and Rita-Louisiana, October 2005. Morbidity and Mortality Weekly Report, 55(2), 31-32.

Chou, Y.J., Huang, N., Lee, C.H., Tsai, S.L., Chen, L.S., \& Chang, H.J. (2004). Who is at risk of death in an earthquake? American Journal of Epidemiology, 160(7), 688-695. 


\section{References}

Dipplold, L., Lee, R., Selman, C., Monroe, S., \& Henry, C. (2003). A gastroenteritis outbreak due to norovirus associated with a Colorado hotel. Journal of Environmental Health, 66(5), 13-17.

Fein, S.B., Lin, C.T.J., \& Levy, A.S. (1995). Foodborne illness: Perceptions, experience, and preventive behaviors in the United States. Journal of Food Protection, 58(12), 1405-1411.

Finch, C., \& Daniel, E. (2005). Food safety knowledge and behavior of emergency food relief organization workers: Effects of food safety training intervention. Journal of Environmental Health, 67(9), 30-34.

Franke, M.E., \& Simpson, D.M. (2004). Community response to Hurricane Isabel: An examination of Community Emergency Response Team (CERT) organizations in Virginia (Quick Response Research Report 170). Retrieved from http://www.colorado.edu/ hazards/research/qr/qr170/qr170.pdf

Gavagan, T.F., Smart, K., Palacio, H., Dyer, C., Greenberg, S., Sirbaugh, P., Fishkind, A., Hamilton, D., Shah, U., Masi, G., Ivey, R.T., Jones, J., Chiou-Tan, F.Y., Bloodworth, D., Hyman, D., Whigham, C., Pavlik, V., Feigin, R.D., \& Mattox, K. (2006). Hurricane Katrina: Medical response at the Houston Astrodome/ Reliant center complex. Southern Medical Journal, 99(9), 933-939.

Kwon, J., Ryu, D., \& Zottarelli, L. (2007). Food-handling practices and operators' food safety attitudes at faith-based Louisiana organizations that provided hurricane evacuee shelters in 2005. Food Protection Trends, 27, 84-89.

Kwon, J., Wilson, A.S., Bednar, C.M., \& Kennon, L. (2008). Food safety knowledge and behaviors of woman, infant, and children (WIC) program participants in the United States. Journal of Food Protection, 71(8), 1651-1658.

Mead, P.S., Slutsker, L., Dietz, V., McCaig, L.F., Bresee, J.S., Shapiro, C., Griffin, P.M., \& Tauxe, R.V. (1999). Food-related illness and death in the United States. Emerging Infectious Disease, 5(5), 607-625.

Medeiros, L.C., Kendall, P., Virginia, H., Chen, G., \& Dimascola, S. (2001). Identification and classification of consumer food handling behaviors for food safety education. Journal of the American Dietetic Association, 101(11), 1326-1332.

Mokdad, A.H., Mensah, G.A., Posner, S.F., Reed, E., Simoes, E.J., Engelgau, M.M., \& Chronic Diseases and Vulnerable Populations in Natural Disasters Working Group. (2005). When chronic conditions become acute: Prevention and control of chronic diseases and adverse health outcomes during natural disasters. Preventing Chronic Disease, 2, 1-7.

Mokdad, A.H., Stroup, D.F., \& Giles, W.H. (2003). Public health surveillance for behavioral risk factors in a changing environment. Recommendations from the Behavioral Risk Factor Surveillance Team. Morbidity and Mortality Weekly Recommendations and Reports, 52(RR09), 1-12.

National Weather Service. (2010a). Summary of natural hazard statistics for 2008 in the United States. Retrieved from http://www. nws.noaa.gov/os/hazstats/sum08.pdf
National Weather Service. (2010b). Summary of natural hazard statistics for 2009 in the United States. Retrieved from http://www. nws.noaa.gov/os/hazstats/sum09.pdf

Pant, A.T., Kirsch, T.D., Subbarao, I.R., Hsieh, Y.H., \& Vu, A. (2008). Faith-based organizations and sustainable sheltering operations in Mississippi after Hurricane Katrina: Implications for informal network utilization. Prehospital and Disaster Medicine, 23(1), 48-54.

Patil, S.R., Cates, S., \& Morales, R. (2005). Consumer food safety knowledge, practice, and demographic differences: Findings from a meta-analysis. Journal of Food Protection, 68(9), 1884-1894.

Raval-Nelson, P., \& Smith, P.M. (1999). Food safety certification and its impacts. Journal of Environmental Health, 61(7), 9-13.

Redmond, E.C., \& Griffith, C.J. (2003) Consumer food handling in the home: A review of food safety studies. Journal of Food Protection, 66(1), 130-161.

Rodríguez, H., Trainor, J., \& Quarantelli, E.L. (2006). Rising to the challenges of a catastrophe: The emergent and prosocial behavior following Hurricane Katrina. Annals of the American Academy of Political and Social Science, 604, 82-101.

Salvation Army. (2009). The Salvation Army disaster response history. Retrieved from http://www.salvationarmyusa.org/usn/www_ usn_2.nsf/vw-text-dynamic-arrays/190F4B74F5ED5E81852574B 70000119F?openDocument

Sanders, J.M. (2007). Vulnerable populations in an American Red Cross shelter after Hurricane Katrina. Perspectives in Psychiatric Care, 43(1), 30-37.

Scallan, E., Hoekstra, R.M., Angulo, FJ., Tauxe, R.V., Widdowson, M.-A., Roy, S.L., Jones, J.L., \& Griffin, P.M. (2011). Foodborne illness acquired in the United States-major pathogens. Emerging Infectious Diseases, 17(1), 7-15.

Stephen, C., \& Brown, B.J. (2005). The threat of communicable diseases following natural disasters: A public health response. Disaster Management and Response, 3(2), 41-47.

The Henry J. Kaiser Family Foundation. (2005). Survey of Hurricane Katrina evacuees. Retrieved from http://www.kff.org/newsmedia/ upload/7401.pdf

U.S. Department of Homeland Security, Federal Emergency Management Agency. (2008). Hurricane Ike impact report. Retrieved from http://www.fema.gov/pdf/hazard/hurricane/2008/ike/impact_ report.pdf

U.S. Department of Homeland Security, Office for Civil Rights and Civil Liberties. (2008). Special needs populations: Impact assessment source document. Retrieved from http://www.disabilitypreparedness. gov/pdf/ike_snp.pdf

Webster, P.J., Holland, G.J., Curry, J.A., \& Chang, H.R. (2005). Changes in tropical cyclone number, duration, and intensity in a warming environment. Science, 309, 1844-1846. 